\title{
Chapter 8 \\ Standard Number Representations in the Teaching of Arithmetic
}

\begin{abstract}
The paper describes the specific approach towards the choice and use of number representations as developed by the project Mathe 2000.
\end{abstract}

The project Mathe 2000 founded in 1987 at the University of Dortmund is a developmental research project that is based on a conception of mathematics education as a design science. In the past the project has been concerned with developing theoretical concepts and practical materials for the teaching of mathematics at the primary level, including an innovative textbook series. However, the project represents a comprehensive view of mathematics teaching and will be extended to the secondary level. As a special feature of the project, design, empirical research, pre-service and in-service teacher training, and public relations are closely linked and pursued simultaneously. Essential for this approach is the establishment of a "theory-practice network" bringing together all partners of the educational system. Here the "Handbook for Practicing Skills in Arithmetic" ( 2 vols.) has been playing a fundamental role as a basic reference. ${ }^{1}$

The present paper is intended to describe and illustrate a specific feature of this project, namely the development of a "grammar of non-symbolic representations" as suggested in Wittmann 1988. The area that is chosen here is arithmetic, one of the basic areas of mathematics teaching.

The first section of this paper presents ten principles which describe basic views on teaching and learning.

In the second section, the epistemological nature of number representations is elaborated in contrast to their use as methodical instruments in traditional didactics. It will be shown that "representation" is a fundamental idea of mathematics.

The third section is devoted to the problem of selecting standard number representations for teaching arithmetic to which symbolic notations are usually related.

Finally, the use of standard representations is illustrated by means of some teaching units that also represent fundamental ideas of arithmetic.

\footnotetext{
${ }^{1}$ For a broader discussion of the Mathe 2000 approach to primary mathematics see Becker and Selter 1996.
}

E. C. Wittmann, Connecting Mathematics and Mathematics Education, 


\section{Principles of Learning and Teaching}

In spite of differences in detail, most mathematics educators around the world might share the following basic views of learning and teaching: Mathematical concepts are neither innate nor readily acquired through experience and teaching. Instead the learners have to reconstruct them in a continued social process where primitive and only partly effective cognitive structures which are chequered with misconceptions and errors gradually develop into more differentiated, articulated and coordinated structures which are better and better adapted to solving problems. Teachers cannot expect concepts to be readily transferable from teacher to student. As Johannes Kühnel put it neatly at the beginning of this century, the main role of the student is characterized by "activity", not by "receptivity", and correspondingly the main role of the teacher by "organisation", not by "instruction". In interacting with students, the teacher must have a feeling for students' ways of thinking and help them to reconstruct their conceptual structures on a higher level.

The diagram in Fig. 1 is an attempt to capture this "genetic" or "developmental" view on teaching and learning in a system of ten principles in order to make it practical for the design of teaching. The author is well aware that systems of this kind are always scholastic to some extent. Nevertheless, he has found the diagram useful for keeping balance in coping with the many aspects of learning and teaching.

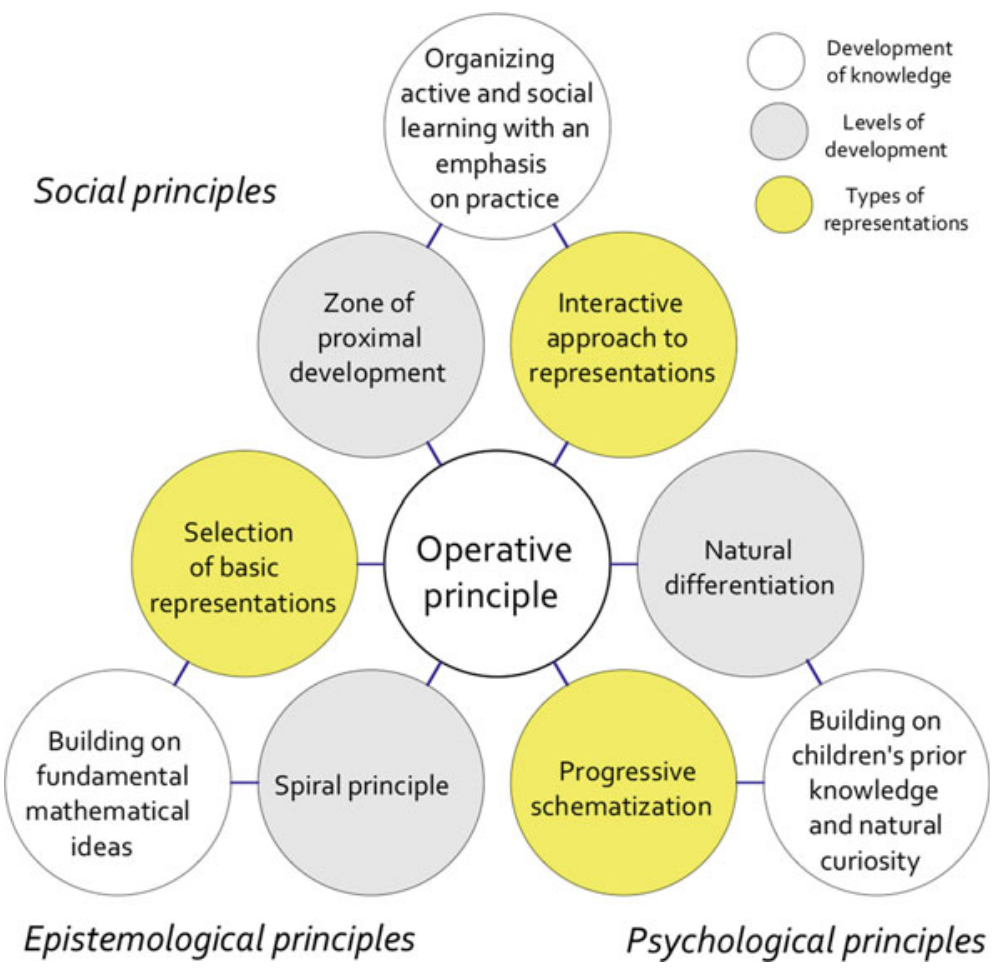

Fig. 1 Principles of learning and teaching 
Explanation of the diagram: The vertices of the triangle are linked to the old didactic triad teacher, subject matter, learner and mark the epistemological, the psychological and the social corners of the diagram: In order to organize learning situations that stimulate students' activities and social interactions (upper vertex) the teacher has to mediate between the genesis of mathematical knowledge on the one hand (left vertex) and the student's developing cognitive repertoire on the other hand (right vertex). The operative principle, derived from Jean Piaget's epistemology and psychology, integrates epistemological, psychological and social aspects, and thus occupies the central position by right.

The "spiral principle" (Bruner 1960, Chap. 3), Vygotsky's principle of the "zone of proximal development" (Wertsch 1985) as well as the principle of "natural differentiation" 2 refer to different levels in the development of knowledge of which the teacher has to be aware.

Three other principles are related to the problem of representing knowledge: one of them speaks in favor of a careful selection of basic representations. Another one recommends a "progressive schematisation" in the representation of knowledge during the learning process (Treffers 1987). The third states that it is impossible for the student to understand even concrete and visual representations directly and postulates their interactive exploration (Schipper 1982; Voigt 1989; Lorenz 1992; Cobb et al. 1992).

Finally, the diagram involves another grouping of the ten principles: the three principles at the left corner together with the central principle form the four epistemological principles. Similarly, we have four psychological principles at the right comer and four social principles on the upper corner. The operative principle belongs to all three groups because of its integrative character.

For the present paper, it is important to note that the problem of representing knowledge plays a fundamental role in the concept of learning and teaching as expressed in the diagram.

\section{The Epistemological Nature of Number Representations}

In order to clarify the background of the principles of Fig. 1 concerned with "representations", it is crucial to examine the history of teaching aids as well as the role of representations in mathematics itself in some detail.

\footnotetext{
2"Natural differentiation" means that the individual student, not the teacher, decides which of the offered tasks he or she should choose and elaborate on.
} 


\subsection{Notes on the History of Number Representations: From Tools of Teaching to Tools of Learning}

The use of teaching aids was postulated for the first time in full weight by Comenius, one of the arch-fathers of didactics, in the 17th century. In his classic "Didactica Magna", published in 1657, he formulated the "golden rule" for all teaching (Comenius 1923, 184-187):

From this a golden rule for teachers may be derived. Everything should, as far as is possible, be placed before the senses. For this there are three cogent reasons. Firstly, the commencement of knowledge must always come from the senses (for the understanding possesses nothing that it has not first derived from the senses).

Secondly, the truth and certainty of science depend more on the witness of the senses than on anything else. For things impress themselves directly on the senses, but on the understanding only mediately and through the senses. It follows, therefore, that if we wish to implant a true and certain knowledge of things in our pupils, we must take especial care that everything be learned by means of actual observation and sensuous perception.

Thirdly, since the senses are the most trusty servants of the memory, this method of sensuous perception, if universally applied, will lead to the permanent retention of knowledge that has once been acquired. If the objects themselves cannot be procured, representations of them may be used. Copies or models may be constructed for teaching purposes. For every branch of knowledge similar constructions (that is to say, images of things which cannot be procured in the original) should be made, and should be kept in the schools ready for use. It is true that expense and labor will be necessary to produce these models, but the result will amply reward the effort.

What Comenius had in mind was to replace the purely verbal teaching practiced in the Middle Ages. His efforts were mainly directed towards elementary science. A famous example for his intentions is his classic textbook "Orbis pictus". The teaching of mathematics is not touched by Comenius, as mathematics, according to the then prevailing Platonic view, belonged to the realm of intellectual and spiritual ideas and therefore was not accessible to concrete or visual representation and perception.

In the 18th century this situation changed completely, when Kant in his philosophic system assigned a quite different status to mathematics. According to Kant, mathematical knowledge is "synthetic", that is depends on basic perceptions of space and time. In the introduction of his "Critique of pure reason", Kant explains this new conception of mathematics in a way which is very close to mathematics teaching (Kant 1943, 9-10):

We might, indeed, at first suppose that the proposition $7+5=12$, is a merely analytical proposition, following (according to the principle of contradiction), from the conception of the sum of seven and five. But if we regard it more narrowly, we find that our conception of the sum seven and five contains nothing more than the uniting of both sums into one, whereby it cannot at all be cogitated what this single number is which embraces both. The conception of twelve is by no means obtained by merely cogitating the union of seven and five; and we may analyze our conception of such a possible sum as long as we will, still we shall never discover in it the notion of twelve. We must go beyond these conceptions, and have recourse to an intuition which corresponds to one of the two- our five fingers, for 
example, or like Segner in his "Arithmetic", five points, and so by degrees, add the units contained in the five given in the intuition, to the conception of seven. For I first take the number 7, and, for the conception of 5 calling in the aid of the fingers of my hand as objects of intuition, I add the units, which I before took together to make up the number 5, gradually now by means of the material image my hand, to the number 7 , and by this process, I at length see the number 12 arise. That 7 should be added to 5, I have certainly cogitated in my conception of a sum $=7+5$, but not that this sum was equal to 12 . Arithmetical propositions are therefore always synthetical, of which we may become more clearly convinced by trying large numbers. For it will thus become quite evident, that, turn and twist our conceptions as we may, it is impossible, without having recourse to intuition, to arrive at the sum total or product by means of the mere analysis of our conceptions.

\section{Kant's statement}

Concepts without intuitive perception are empty, intuitive perceptions without concepts are blind

became the slogan for a big movement among educators who set out to ground teaching on visual representations.

One of the first to apply Kant's view to the teaching of mathematics was Pestalozzi. In his "ABC der Anschauung" he attempted to teach basic facts about natural numbers and fractions through precisely defined chains of exercises related to the "Table of units" (Fig. 2) and to the decomposition of a square (Pestalozzi 1803). Although in theory perception was related to activity ("Selbsttätigkeit") Pestalozzi's practical proposals lacked far behind his postulate, as we understand it nowadays.

\begin{tabular}{|c|c|c|c|c|c|c|c|c|c|}
\hline 1 & 1 & I & 1 & 1 & 1 & I & I & I & 1 \\
\hline II & II & II & II & II & II & II & II & II & II \\
\hline III & III & III & III & III & III & III & III & III & III \\
\hline IIII & IIII & IIII & IIII & IIII & IIII & IIII & IIII & IIII & IIII \\
\hline IIIII & IIIII & IIIII & IIIII & IIIII & IIIII & IIIII & IIIII & IIIII & IIIII \\
\hline IIIIII & IIIIII & IIIIII & IIIIII & IIIIII & IIIIII & IIIIII & IIIIII & IIIIII & IIIIII \\
\hline IIIIIII & IIIIIII & IIIIIII & IIIIIII & IIIIIII & IIIIIII & IIIIIII & IIIIIII & IIIIIII & IIIIIII \\
\hline IIIIIIII & IIIIIIII & IIIIIIII & IIIIIIII & IIIIIIII & IIIIIIII & IIIIIIIII & IIIIIIII & IIIIIIII & IIIIIIII \\
\hline IIIIIIIII & IIIIIIII & IIIIIIIII & IIIIIIIII & IIIIIIII & IIIIIIIII & IIIIIIII & |1!IIIIIII & IIIIIIII & IIIIIIIII \\
\hline
\end{tabular}

Fig. 2 Pestalozzi's "Table of units"

Along the same lines Tillich wrote a textbook for teaching arithmetic which was based on a kit of rods, a precursor of the Cuisenaire rods (Tillich 1806). Beyond mere perception an element of "activity" on part of the student is implicit in Tillich's approach. It was Froebel who some years later made this element explicit in his theoretical approach to cognition. However, it is important to note that here "activity" was understood as completely prescribed behavior. No room was left to the student's 
own initiative, as is shown by the following section "Representation and perception of the number series as a continuous whole" from Froebel's course (Froebel 1826/1966, 289-290, transl. E.Ch.W.). Essentially the basic representation is nothing but one column of Pestalozzi's “Table of units":

Count from One to Ten and each time draw as many vertical strokes (of a certain length) as the number word indicates, that is One I, Two II, Three III, etc., one below the other.

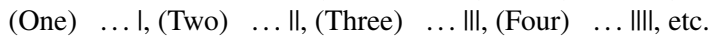

Have you done so? What have you done?

We have counted from one to ten, and each time, etc.

Well! You have represented the natural series of all numbers from one to ten. What have you represented?

Emphasizing, perceiving and getting aware of the interaction between word and set, number itself:

- starting from the number words:

Teacher and students recite in unison by pointing to the represented series:

One is I (one One), Two is II (two Ones), Three is III (three Ones), etc.

- starting from the number or set:

Teacher and students recite in unison by pointing to the sequence

I is One, II is Two, III is Three, etc.

Word and set merge, appear as one thing, number is perceived in its pure form:

| One is One, || Two is Two, III Three is Three, etc.

Recitation by teacher and students as before.

During the 19th and 20th century a wide variety of teaching aids for arithmetic was invented. Although many of these inventions aimed at student "activity" the restrictions from the times of Tillich and Froebel were never overcome. Teaching aids remained tools in the hands of the teacher and were subordinated to didactic systems which were based on the empiricist credo that knowledge is something to be transmitted from teacher to student. It was firmly believed that teaching aids work the better the more their use is prescribed by the teacher in all details. This belief was taken over by theories of learning arising in the 19th century which recognized the insufficiency of the "perception channel" for learning and introduced the "activity channel". These advanced empiricist theories were further elaborated in the 20th century and exerted a great influence on didactics and on the teaching practice'. A good example from our time is Galperin's theory of learning and teaching in which the "reflection of the objective reality in the mind" is pursued by activities prescribed in detail step by step (cf., Gravemeijer 1994, Sect. 2, for an excellent analysis of the traditional use of manipulatives and its limitations).

A typical application of this narrow didactic view is provided by the "transition beyond ten" in traditional German didactics for grade 1 . In order to calculate $7+5$ Cuisenaire rods (or counters) must be arranged in a definite way (Fig. 3) and the calculation must follow prescribed steps:

$$
7+3=10, \quad 5-3=2, \quad 10+2=12 .
$$




\begin{tabular}{|l|l|l|}
\hline 7 & \multicolumn{2}{|c|}{5} \\
\hline 10 & \multicolumn{2}{|c|}{} \\
\hline
\end{tabular}

Fig. 3 Using Cuisenaire rods for deriving results

In the past 20 years "constructivist" conceptions of learning and teaching have gained ground and have shed a quite different light on "teaching" aids. In Europe this movement was very much influenced by Piagetian psychology. Already in the late sixties Jean Piaget stated the shortcomings of traditional visual methods very clearly (Piaget 1970, 71-72):

One of the causes of the slowness with which the active methods have been adopted is the confusion that sometimes occurs between the active methods and the intuitive methods. A certain number of pedagogues in fact - and often in the best possible faith - imagine that the latter are an equivalent of the former, or at least that they produce all the essential benefits that can be derived from the active methods.

We are faced here, moreover, with two distinct confusions. The first, which has already been mentioned, is that which leads people to think that any "activity" on the part of the student or child is a matter of physical actions, something that is true at the elementary levels but is no longer so at later stages when a student may be totally "active", in the sense of making a personal rediscovery of the truths to be acquired, even though this activity is being directed toward interior and abstract reflection.

The second confusion consists in believing that an activity dealing with concrete objects is no more than a figurative process, in other words nothing but a way of producing a sort of precise copy, in perceptions or mental images, of the objects in question. In this way it is forgotten that knowledge is not at all the same thing as making a figurative copy of reality for oneself, but that it invariably consists of operative processes leading to a transformation of reality, either in actions or in thought. It is also forgotten that the experience brought to bear on the objects may take two forms, one of which is logico-mathematical and consists in deriving knowledge, not from the objects themselves, but from the actions as such that modify the objects.

Since all this has been forgotten, the intuitive methods come down, quite simply to a process of providing students with speaking visual representations, either of objects or events themselves, or of the result of possible operations, but without leading to any effective realization of those operations. These methods, which are, moreover, traditional, are continually being reborn from their own ashes and do certainly constitute an advance to purely verbal or formal teaching techniques. But they are totally inadequate in developing the child's operative activity, and it is only as a result of a simple confusion between the figurative and the operative aspect of thought that it has been believed possible to pay tribute to the ideal of the active methods while at the same time giving concrete form to the subject matter of education in this purely figurative guise.

In his critical analysis of the mass of new materials and diagrams introduced into the teaching of mathematics by "New Math", Schipper discovered an important fact (Schipper 1982): Children do not understand these representations immediately nor automatically. On the contrary, they must learn them as a kind of additional subject matter. 
In the meantime this fact has been validated by a variety of research findings (Radatz 1986; Voigt 1989; Jahnke 1989; Lorenz 1992). Krauthausen (1994) has summarized the new view on concrete and visual representations, diagrams etc. in six propositions (Krauthausen 1994, 30-35):

1. What primarily counts are mental images of concepts. Visual representations can support these to some extent.

2. Mental images are not just copies of external representations, but they are formed by the constructive activity of the individual.

3. These constructions are idiosyncratic, that is, they are determined by the experiences and personal knowledge of the individual.

4. Concrete and visual representations are no, speaking pictures', they do not fulfil the expected function as carriers of mental images per se.

5. Concrete and visual representations are neither only aids for the so-called'slow learners' nor is their use restricted to the early steps of the learning process. They are important for all children and they are useful for the whole duration of the learning process.

6. Concrete and visual representations are not automatically the better, the more specifically they represent the intended concept. ,Perfect' representations can be counterproductive. In order to fulfill their function good representations must involve a certain vagueness.

In this new view representations of mathematical structures are no longer considered as tools of the teacher for transmitting knowledge, but as tools of the learner for doing mathematics. Their status is no longer a didactic, but an epistemological one (Wittmann 1993).

Representations of knowledge develop with the cognitive repertoire of the individual. They have to be constructed and re-constructed in an extended interactive process as a kind of language and as a field for exploration. It is through applying and testing these representations in new contexts that the individual understands and uses them better and better.

\subsection{Representations in Mathematics}

The shift from didactics to epistemology draws the attention to the true origin of representations, namely to mathematics itself. Kaput (1987) and Dörfler (1991) have very clearly pointed out the fundamental role which is played by representations of mathematical objects in mathematical research. Even if systematic-deductive presentations of mathematical theories do not point it out explicitly, mathematical theories do not only involve concepts, theorems, and algorithms, but also the construction of objects to which they pertain. These constructions form a "quasi-reality" which allows for experimentally investigating concepts, conjectures and proofs. So within 
the development of a theory there is a continuous interplay between descriptions and constructions. For example, the exponential function can be described as a homomorphism of the additive group of real numbers into the multiplicative group of real numbers, and it can also be constructed by defining its values step by step for natural numbers, integers, fractions and irrational numbers. In a similar way, a group can be defined by means of axioms, and it can be constructed as a permutation group. Within every theory we also find attempts to characterize classes of objects by showing how they are constructed out of well-known special objects. Theorems of this kind are called representation theorems (Kaput 1987). A good example is provided by the complete classification of finite simple groups achieved in the early eighties.

In higher mathematics representations are in general symbolic. However, the early history of mathematics demonstrates very clearly the basic role of counters ("calculi") in the development of arithmetic (cf., Damerow/Lefèvre 1981). It is interesting to note that the ancient Greeks discovered and proved the first theorems on even, odd and figurate numbers by forming appropriate patterns of counters (cf., Becker 1954, 34-40), and it is equally interesting to realize that eminent research mathematicians emphasize the explanatory power of these patterns for the foundations of arithmetic even today (cf., Penrose 1994, 48-50).

Considered through the epistemological lens, representations have an amphibianlike status: On the one hand they are quasi-real or, as in the case of counters, even real, on the other hand they carry theoretical relationships. As a consequence the use of representations is not restricted at all to founding or illustrating concepts. On the contrary: Representations can be used and are used in the full process of making mathematics including mathematizing, discovering, reasoning, and communicating. The rise of experimental mathematics due to efficient computer software bears witness to this fact.

Because of their amphibian-like status representations can be used to model real situations and they can be used to model mathematical structures. In the first case they are "more abstract" than what they model, in the second case they are "more concrete".

By working with representations of mathematical objects, even proofs of general statements become possible, as explained in Piaget's epistemology: According to Piaget, mathematical knowledge is not derived from the objects themselves, but from operations with objects in the process of reflective abstraction ("abstraction réfléchissante", Beth/Piaget 1961, 217-223). When it is intuitively clear that the operations applied to a special object can be transferred to a class of objects the relationships based on these operations are general. An instructive example is given by Dress (1974) who describes in detail how he found and proved a theorem on the Burnside ring of finite groups by elaborating the special case $A_{5}$, the alternate group of order 5 .

In the process of learning the interplay between formal descriptions of mathematical structures by means of symbols ("signs") on the one hand and their quasi-real representations ("referents" or "objects") on the other hand is reflected in the epistemological triangle of "concept, sign and object" introduced by Steinbring (1994) (Fig. 4). 


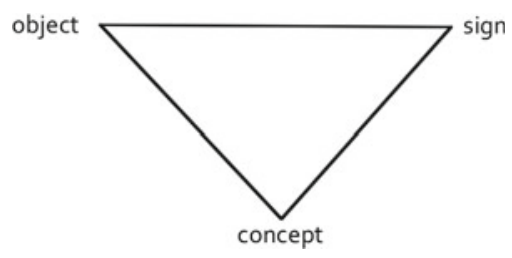

Fig. 4 The epistemological triangle

As a simple example think of the first natural numbers, denoted by the signs $1,2,3, \ldots$ and represented by sets of counters. In the early stages of the development of the number concept, counters are more meaningful and more operative than the signs. But the more the signs are filled with meaning and carry relationships, the more they contribute to better understanding operations with counters. At higher levels signs and connected symbolic operations can well be used as representations of new concepts and become accessible to experimental investigation.

By analyzing a number of lesson transcripts, Steinbring has shown that problems of understanding, ruptures, mistakes, misunderstandings etc. in the teaching/learning process are often due to treating or seeing the upper corners of the epistemological triangle in isolation or to subordinating one corner to the other one. In order to overcome the "socially conventionalized strictness of sign attribution" he argues in favor of "a conceptual flexibility for constructing references between symbol and referent" (p. 381).

\section{Selection of Standard Number Representations}

For instructional design the message resulting from the preceding analysis seems clear. In distinct opposition to the flood of "teaching aids" offered on the market manipulatives should be carefully selected: "Less is More".

The present section gives an account of how Mathe 2000 has approached the problem of selecting and designing a set of standard number representations for the teaching of arithmetic.

\subsection{Criteria for Selecting and Designing Standard Representations}

The following criteria for selecting and designing standard representations for a given domain of teaching have been developed and continuously modified in the process of design. On the one hand they re-phrase theoretical results of the preceding sections, on the other hand they reflect practical conditions and constraints of teaching. 


\section{Criterion 1:}

The number of standard representations for teaching a given domain should be small so that the students can become thoroughly familiar with them in the time available for learning. In order to avoid ruptures in the learning process, these standard representations should be compatible with one another.

\section{Criterion 2:}

The standard representations should capture the fundamental mathematical ideas underlying the given domain as far as possible. This secures mathematical substance and opens up extended opportunities for students' structuring activities as the basis of mental images.

\section{Criterion 3:}

Standard representations should be available in two isomorphic user-friendly versions: a big one for the purpose of demonstration in the class, a small one for student's use. This facilitates the transition from individual and small group work to classroom communication and vice versa.

The big standard representations should be fixed on the walls of the classroom and be freely accessible, the small versions should be ready at hand.

\section{Criterion 4:}

Each student should be equipped with personal copies of the standard representations. Therefore the small versions must be made of low cost materials (as a rule paper).

Of course the leading criterion for selection and design is the second one. Its application depends crucially on the identification of fundamental ideas of the given domain, a task that is taken up in the following section for arithmetic.

\subsection{Fundamental Ideas of Arithmetic}

A developmental approach to teaching a given field of knowledge cannot be based on systematic-deductive presentations. What is needed instead is a genetic picture of this field. Here Bärbel Inhelder's suggestion to identify "fundamental ideas" which can be elaborated in the process and progress of learning has proved as a striking method (Bruner 1960, Chap. 2).

The following list of fundamental ideas of arithmetic has been based on the operative principle: In any domain of knowledge there are

- "objects"

- "operations" which can be applied to the objects and

- the "effects" of the operations on the properties and relationships of objects.

In arithmetic the "objects" are numbers, sums, differences, products, quotients, functions, etc. The "operations" are counting, adding, subtracting, multiplying, dividing, etc. The "effects" are expressed by the laws of arithmetic and all kinds of number patterns. 
This operative structure is visible in the following list of fundamental ideas of arithmetic:

\section{1. "Number as a synthesis of the ordinal and the cardinal aspect"}

The natural numbers form an infinite series which is covered in counting (ordinal aspect). They also serve as cardinal numbers.

\section{2. "Operating with numbers"}

The laws of arithmetic provide the frame for (more or less sophisticated) mental and informal calculations as well as for algorithms. The laws of arithmetic are preserved in the larger domains (fractions, integers, real numbers).

\section{3. "Decimal system"}

Our conventional number system is based on the number ten. An important role is also played by the number 5 as a half ten ("Power of five", Flexer 1986). The thousand triade is repeated in the millions, milliards, etc.

\section{4. "Standard algorithms"}

Standard algorithms allow for reducing calculations with numbers to calculations with digits. The algorithms can be automatized and implemented on hand-held calculators and computers.

\section{5. "Number patterns"}

Arithmetic is rich in problems and number patterns (number theory, combinatorics).

\section{6. "Numbers in the environment"}

Natural numbers can be applied as cardinal numbers, ordinal numbers, magnitudes, operators and codes.

\section{7. "Arithmetic as a language"}

Real situations can be mathematised by using the conceptual structures of arithmetic.

\subsection{Standard Number Representations}

With the criteria of Sect.3.1 and the list of fundamental ideas of Sect. 3.2 in mind, available manipulatives have been checked, selecting those which seemed most appropriate for the teaching units that were being developed.

It turned out very quickly that some of the traditional number representations were optimal solutions for our purposes (for example, the Hundred Table) and that others could be easily adapted (for example, the Hundred array). The remaining gaps were filled by newly developed materials (for example, posters for the addition and multiplication tables).

Some well-known and popular number representations did not meet our criteria and consequently had to be dropped. For example, the Cuisenaire rods, though offering a good potential for structuring activities in grade 1 and in part in grade 2, do not incorporate the "power of five" (criterion 2, fundamental idea 3), cannot be extended to grades 3 and 4 (criterion 1), and are too expensive to be available for every student (criterion 4). Moreover, when it comes to operating on sums, the Cuisenaire rods are 
less flexible than the Twenty frame and counters (criterion 2, fundamental idea 2). For similar reasons base ten blocks had to be excluded from the list.

The following manipulatives were chosen as standard number representations (cf. Wittmann and Müller 1990, 9-12, 1992, 10-12). They are listed here according to their correspondence to the fundamental ideas of arithmetic as they appear grade by $\operatorname{grade}^{3}$ :

\section{"Series of Numbers"}

Grade 1:

- Twenty Row (Circles in groups of five, numbered from 1 to 20 or alternately with entries $5,10,15,20$ )

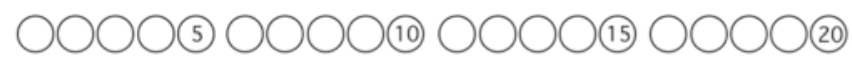

Grade 2:

- Hundred Row (100 circles, coloured in groups of five, with entries 5, 10, 15, 20)

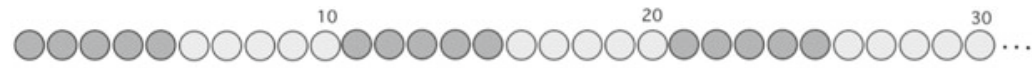

Grade 3:

- Thousand Row (yardstick-like representation of numbers from 1 to 1000 with entries $25,50,75,100,125,150, \ldots$ )

\footnotetext{
${ }^{3}$ At this place a general comment seems appropriate. In German mathematics education there has been a steady work on teaching aids since the 19th century. This work has been accompanied by coining short and fitting names for teaching aids and a didactical language for their use. The German language has been facilitating this process by certain linguistic characteristics, for example, the easy formation of compounds.

When the present chapter and the textbook DAS ZAHLENBUCH were translated into English it has been impossible at some places to find suitable English terms. Therefore, the author has taken the freedom to coin new words that are more or less literal translations from the German. For English-speaking readers these terms may need habituation, and it is not unlikely that some might reject them together with the didactical context into which they belong.

It cannot be ignored that there is a general problem in translating meanings from one language and one cultural context into another one. In Hughes (1994, 311-312) the English poet Ted Hughes expresses his irritation when he realized that an urban American poet had degraded his poems. Hughes explains this lack of understanding with the spread of a lingua franca that is unavoidably developing in a multicultural society like the US. This second language has a tendency of becoming superficial and of ironing out deeper meanings, and it induces the speakers of this language to consider themselves as superior and to ignore what is communicated in other languages.

To some extent this problem also exists in mathematics education, and it becomes especially apparent at international conferences. The use of English as a lingua franca of mathematics education is a double-edged sword. Mathematics educators in non-English-speaking countries are well-advised to preserve and to cultivate their context and stick to proven achievements that are not reflected in the lingua franca.
} 


\section{Grade 4:}

- Number line as a mental model indicated by representations of various sections of the number line.

Hassler Whitney's idea of the empty number line (Treffers and de Moor 1990; Gravemeijer 1994, p. 120 ff.) has been integrated in grades 3 and 4. Figure 5 (from Treffers and de Moor 1990, 56-57), shows how this idea is used by children.

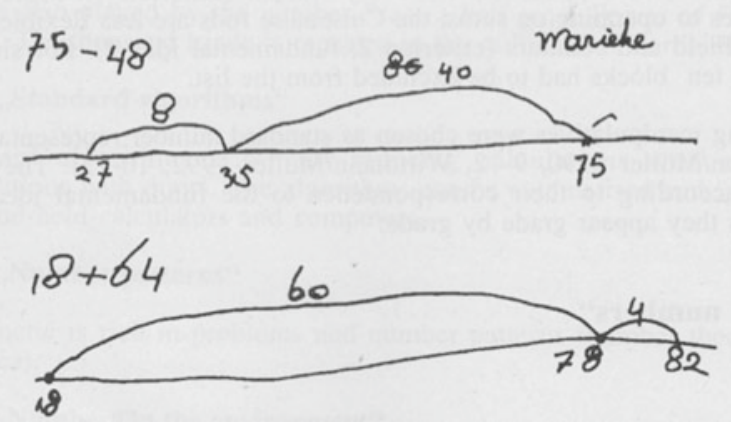

Fig. 5 Reasoning with the empty number line

\section{“Calculating”}

Grade 1:

- Counters (one side red, other side blue) for representing numbers, sums and differences as well as patterns

- Number cards for numbers 0 to 20 (one side: numbers written with digits, other side: corresponding pattern of dots) (Fig. 6)

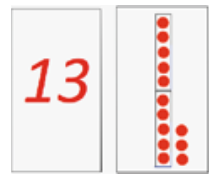

Fig. 6 Number cards 
- Twenty frame and counters for a systematic study of the addition table (Fig. 7)

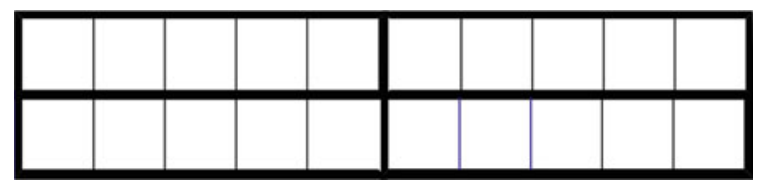

Fig. 7 Twenty frame

- Addition chart (big version $90 \mathrm{~cm}$ x $120 \mathrm{~cm}$ with colored boxes for demonstrating the operative structure of the addition table (Fig. 8).

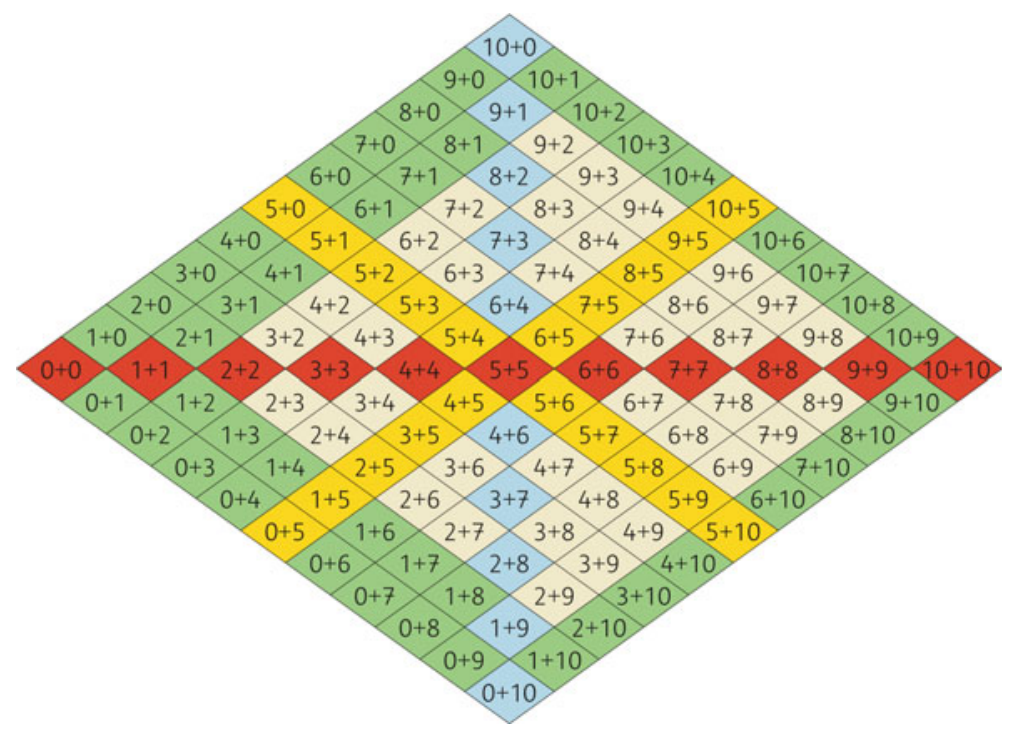

Fig. 8 Addition chart

Grade 2:

- Hundred array (subdivided into four 25 squares according to the "power of five") and "cover card" for showing numbers from 1 to 100 (Fig. 9). 


\begin{tabular}{|c|c|}
\hline 1000 & 1000 \\
\hline 000 & 10 \\
\hline 0 & 0 \\
\hline 000 & 0 \\
\hline 000 & 0 \\
\hline 00 & 0 \\
\hline 0 & 0 \\
\hline 00 & \\
\hline & \\
\hline & \\
\hline
\end{tabular}

000000000 0000000000 000000000 000000000 000000000 10000

Fig. 9 Hundred chart with cover card

- Bar/dot representation: As a shorthand notation, bars are used for tens and dots for ones (Fig. 10).

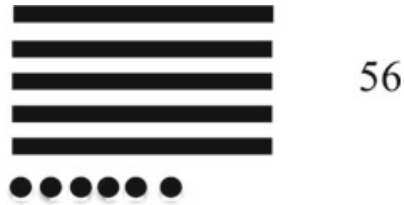

Fig. 10 Bar/dot representation

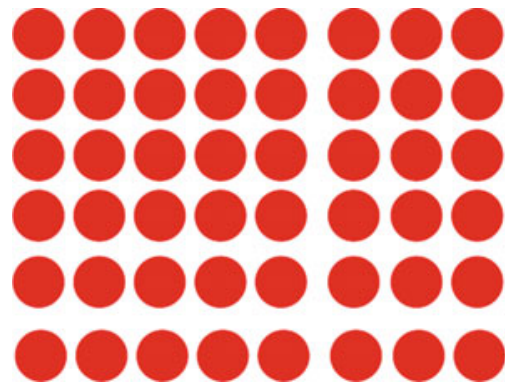

Fig. 11 Dot array

- Dot arrays: These arrays are used for representing products (Fig. 11).

- Hundred array and "angle card" for representing products (Fig. 12). 

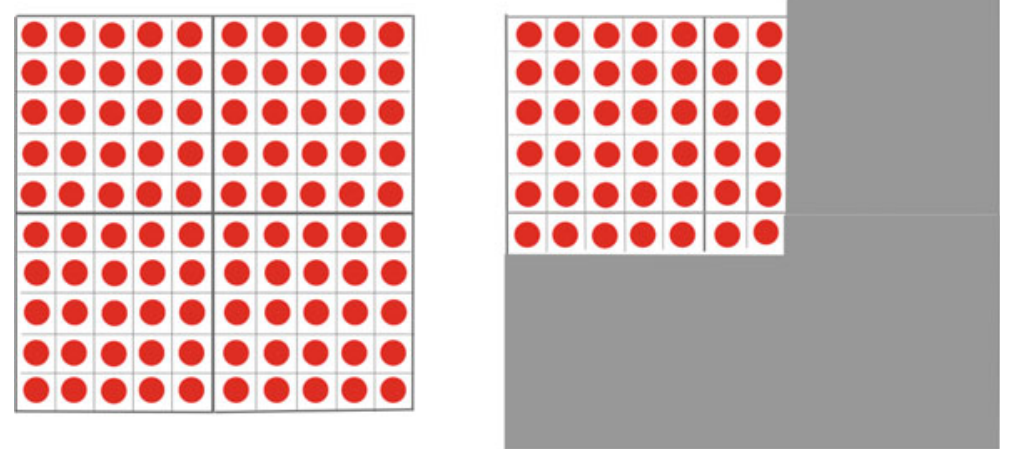

Fig. 12 Hundred array and angle card

- Multiplication grid: The subdivision of dot arrays by a line or a cross gives rise to a shorthand notation for computing products according to the distributive law (Fig. 13).

The multiplication grid is very useful when it comes to calculating products of larger numbers.

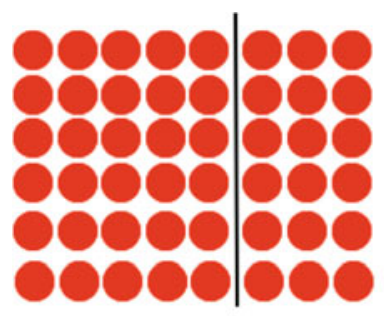

$$
\begin{array}{c|c|c}
\cdot & 5 & 3 \\
\hline 6 & 30 & 18
\end{array}
$$

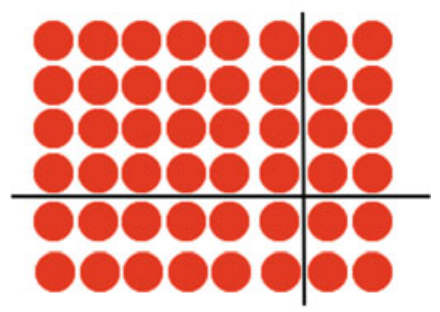

$$
\begin{array}{c|c|c|c}
. & 6 & 2 & \\
\hline 4 & 24 & 8 & 32 \\
\hline 2 & 12 & 4 & 16 \\
\hline 48
\end{array}
$$

Fig. 13 Multiplication grid

- Multiplication system (big version $90 \mathrm{~cm} \times 120 \mathrm{~cm}$ ): Systematic overview of the multiplication table where the products are represented as strings of circles.

- Multiplication chart (big version $90 \mathrm{~cm} \times 120 \mathrm{~cm}$ ), structure analogous to the Addition chart (Fig. 14). 


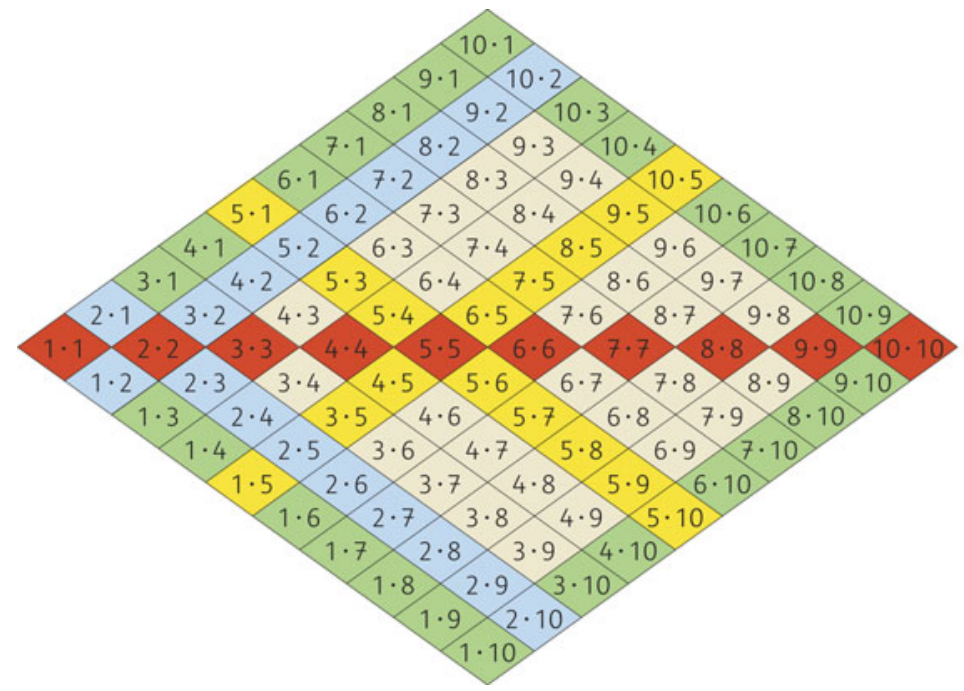

Fig. 14 Multiplication chart

Grade 3:

- Thousand array (Wittmann and Müller 1992, p. 1 0): 10 copies of the hundred array in linear order. This array is useful for representing numbers and for supporting calculations (Fig. 18).

\section{“Decimal System”}

\section{Grade 1:}

- Twenty frame (Fig. 7)

\section{Grade 2:}

- Hundred chart (Fig. 15) 


\begin{tabular}{|c|c|c|c|c|c|c|c|c|c|}
\hline 1 & 2 & 3 & 4 & 5 & 6 & 7 & 8 & 9 & 10 \\
\hline 11 & 12 & 13 & 14 & 15 & 16 & 17 & 18 & 19 & 20 \\
\hline 21 & 22 & 23 & 24 & 25 & 26 & 27 & 28 & 29 & 30 \\
\hline 31 & 32 & 33 & 34 & 35 & 36 & 37 & 38 & 39 & 40 \\
\hline 41 & 42 & 43 & 44 & 45 & 46 & 47 & 48 & 49 & 50 \\
\hline 51 & 52 & 53 & 54 & 55 & 56 & 57 & 58 & 59 & 60 \\
\hline 61 & 62 & 63 & 64 & 65 & 66 & 67 & 68 & 69 & 40 \\
\hline 71 & 72 & 73 & 74 & 75 & 76 & 77 & 78 & 79 & 80 \\
\hline 81 & 82 & 83 & 84 & 85 & 86 & 87 & 88 & 89 & 90 \\
\hline 91 & 92 & 93 & 94 & 95 & 96 & 97 & 98 & 99 & 100 \\
\hline
\end{tabular}

Fig. 15 Hundred chart

Grade 3:

- Square/bar/dot representation of numbers (Fig. 16)

- Place value chart and counters (Fig. 17)

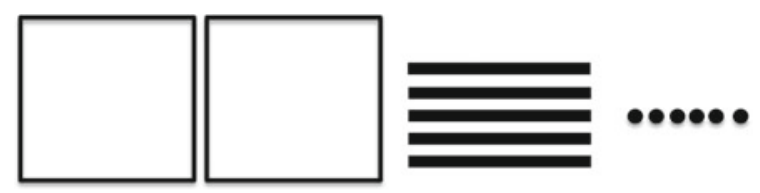

Fig. 16 Square (bar/dot representation

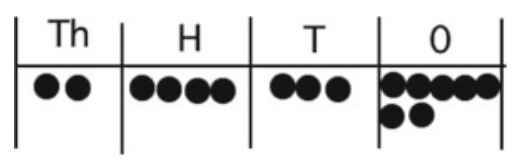

Fig. 17 Place value chart and counters 
- Thousand book (Wittmann/Müller 1990, p. 10, 14ff.)

This teaching aid is a continuation of the Hundred chart. It reflects the triadic structure of the decimal system: 10 unit squares form a line, 10 lines form a page, and 10 pages form the whole book. Each page is isomorphic to the hundred chart (Fig. 18). The pages can be folded to make a Leporello (Fig. 18). The back of the Thousand book shows the Thousand array (Fig. 19)

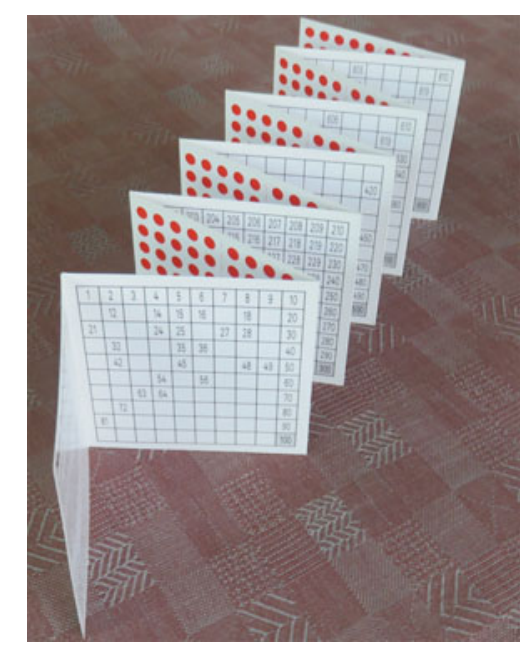

Fig. 18 Thousand book

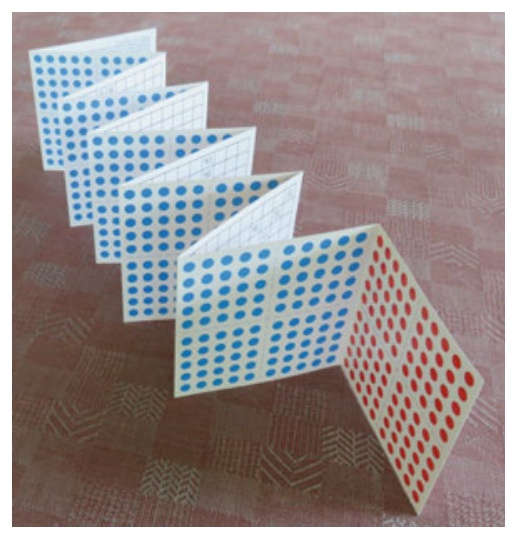

Fig. 19 Thousand array 
Grade 4:

- Place value chart and counters with further columns at least up to the million

- Million book: The Thousand book if folded together is a square, like one unit field of the book itself. With this bigger square, the construction of the Thousand book is repeated on a higher level: 10 Thousand books (folded to squares) make one line (10000), 10 lines make one page (100000), and ten pages make the whole Million book. In this book every number from 1 to 1000000 has a definite place. For example, 365278 is the 278th number in the 366th thousand book.

The construction can be repeated infinitely: The Million book, when folded together is again a square, 10 squares make a line, 10 lines make a page, 10 pages make the Milliard book, and so forth.

The triadic structure of the place value chart and the series of Thousand book, Million book, Milliard book, $\cdots$ reflect the triadic writing of natural numbers, for example 423365278 . Within each triad the calculations are identical.

- Digit cards for digits 0 to 9 (Fig. 20)

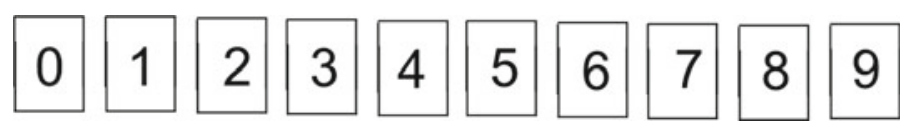

Fig. 20 Digit cards

\section{"Standard Algorithms"}

Grade 3:

- Place value chart for addition and subtraction

Grade 4:

- Place value chart for division

- Napier's strips: As a preliminary version of long multiplication a diagram used in the Middle Ages (written version of Napier's rods) can be easily derived from the Multiplication grid (Fig. 21). 


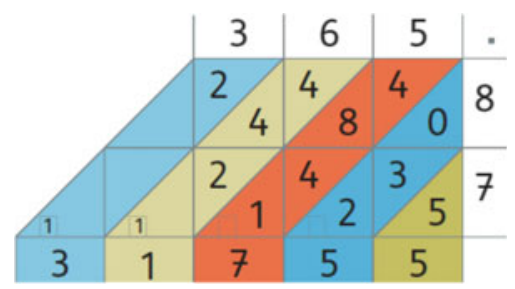

Fig. 21 Napier's strips

\section{"Number Patterns"}

All grades:

- Patterns of counters, dot arrays, place value chart and counters

\section{"Numbers in the Environment" and "Arithmetic as a Language"}

Over the grades:

- Yardsticks, square metre (made of paper), cubic metre (made of wooden rods), clocks, calendars, money, scales and weights, measuring vessels.

\section{Some Teaching Units}

The following brief sketches of teaching units developed in the project Mathe 2000 are to indicate how standard number representations can serve as tools for the learner in mathematizing, discovering, reasoning and communicating during the entire process of active and social learning.

It should become clear that the students enjoy all freedom in using the manipulatives, including the freedom not to use them, in other words, that standard representations do not necessarily involve standard ways of teaching and learning. On the contrary: If freed from a didactic system, standard representations, which by their very design are related to fundamental mathematical ideas, greatly contribute to a stable learning environment and stimulate the learning process in the same way as a rich and stable language environment in early childhood fosters the process of language acquisition. As convincingly shown by Dewey (1976) a learning environment carefully grounded on the subject matter of teaching is even a pre-condition for the success of open learning processes. 
The following descriptions indicate the potential of the units which in real teaching is only rarely exhausted. The units can be used very flexibly and leave much room for natural differentiation. For further details the reader is referred to the "Handbook of Practicing Skills in Arithmetic” (Wittmann/ Müller 1990, 1992).

\subsection{The Twenty Frame and the Addition Table (Grade 1)}

In opposition to the traditional method the (open) number space 1 to 20 is introduced as a whole at the beginning of grade 1 fairly quickly and considered in several rounds from different sides. Similarly, the addition table is studied in a holistic way. After considering "additive situations" in the environment and eliciting children's spontaneous addition strategies, a first systematic study of the addition table is built upon the Twenty frame. Children can represent and solve addition tasks in different ways. In principle there are no prescribed methods. It is only by trying different placements and groupings of counters, by changing counters and by discussions in small groups or in the class that the individual child will discover relationships and learn to use them according to his or her personal preferences in mastering the addition table. Of course the "power of five" will be experienced by all children as a very useful strategy which, however, is to be used flexibly. The Twenty frame supports this strategy.

For example, let us consider the task $7+5$.

Representation A (Fig. 22): 7 red counters are placed in the first row, 5 blue ones in the second one. The two fives on the left side are grouped together to make 10 .

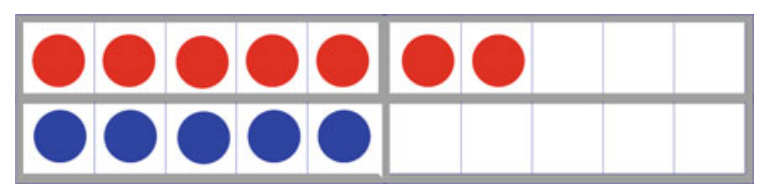

Fig. 22 First solution of $7+5$ with the twenty frame

Representation B (Fig. 23): Again 7 red counters are placed in the first row, 3 of 5 blue counters fill the first row and leave two counters for the second row. This is the traditional "transition beyond ten".

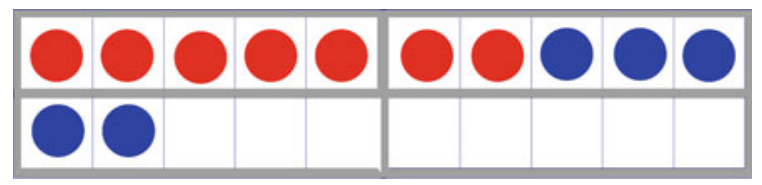

Fig. 23 Second solution of $7+5$ with the twenty frame 
Representation C (Fig. 24): One red counter is translated to the second row. Before calculating the task $7+5$ is changed into $6+6$, a task with the same result which, however, is easier for many children.

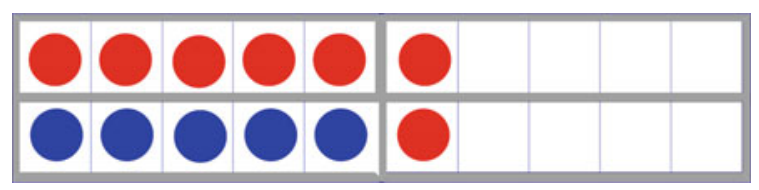

Fig. 24 Third solution of $7+5$ with the twenty frame

It should be mentioned that this approach to the addition table via the Twenty frame is essentially identical with the approach suggested by Treffers via the arithmetic rack (cf., Gravemeijer 1994, 71-72).

\subsection{Multiplication Chart (Grade 2)}

This poster is used for a systematic study of the operative relationships between multiplication tasks. From the rich source of activities, a unit for practicing multiplication facts combined with discovery and proof is chosen.

The students are asked to calculate the following pairs of tasks on the Multiplication chart:

$$
1 \cdot 1=\quad, 2 \cdot 2=\quad, 3 \cdot 3=\quad, 4 \cdot 4=\quad, 5 \cdot 5=\quad \ldots 10 \cdot 10=\quad .
$$

Most children will find out that the results of each vertical pair differ by 1 . Some will discover the missing partners of the first and the last task in the first row $(0 \cdot 2$ and $9 \cdot 11$ ) and state that the difference is again 1.

By means of counters children can be guided to look at special cases and to find an operative proof why the difference must be 1 (Fig. 25). For example, the pattern of $5 \cdot 5$ has one row, that is 5 counters, more than the pattern of $4 \cdot 6$. The latter has one column, that is 4 counters, more than the former. Therefore $5 \cdot 5$ must be 1 more than $4 \cdot 6$. The same operations can be applied to other patterns. Stimulated by this operative series, students can investigate other adjacent pairs of rows or columns on their own and look for similar relationships. 

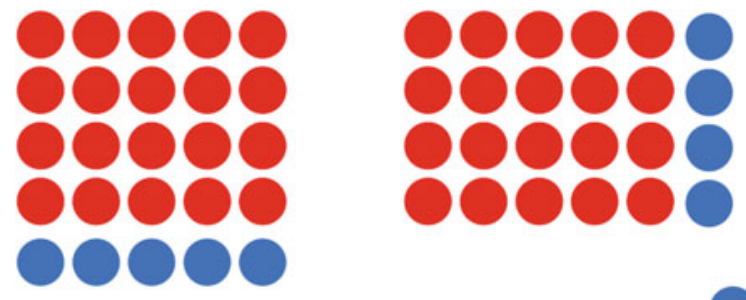

Fig. 25 Number pattern

\subsection{An Introduction into the Thousand Book (Grade 3)}

"Introducing" the Thousand book means to have the children explore its structure without predetermining objectives. At the beginning of the unit, each child gets a personal copy of the book and is stimulated to think about it. After some time the children are asked to report on their ideas. For the teacher this "local finding" yields valuable information for further teaching.

If the question "Why is the Thousand book called a'book'?" is not asked spontaneously by the children, the teacher has to pose it and to make sure that the students become aware of the "lines" and "pages".

A good stimulation for a deeper exploration is the following suggestion:

"Find tasks with the result 1000 and write them down on a sheet of paper!" This open problem allows for "natural differentiation". Some children stick to simple problems like $500+500,600+400,999+1$. Others find tasks like $10 \cdot 100,50 \cdot 20$ or $40 \cdot 25$ and go beyond 1000 , for example $10000-9000=1000$.

Another good problem for studying the back of the Thousand book, the Thousand array, is to divide 1000 ("smarties") among $2,3,4, \ldots, 10$ children.

This introductory unit shows very clearly that the structure of the number space 1 to 1000 is not "taught" in the traditional sense. It is "learned" through exploring problems related to its structure. During the exploration there is plenty of room for students' own initiative and choice.

\section{4 “Always 22" (Grade 3)}

This unit is based upon the following rule:

(1) Select three digit cards from the nine cards $1, \ldots, 9$ (for example 2, 4, 7)

(2) Form all possible two-digit numbers $(24,27,42,47,72,74)$ and add them

$$
(24+27+42+47+72+74=286)
$$


(3) Divide this sum by the sum of the three selected digits

$$
(2+4+7=13, \quad 286: 13=22)
$$

There are many (84) triples of digits, and different children will make different choices. The more surprising is the fact that independently of the selected digits the result of the division task is always the number 22 (giving the unit its name) provided the calculations are correct.

For one case the explanation of this observation is easy, namely when the sum of digits is exactly 10 (for example for the digits $2,3,5$ ). Representing the numbers in the place value chart shows how the sum of digits is related to the sum of numbers: The sum of digits appears twice in the Ones column and twice in the Tens column. Division by the sum of digits necessarily yields 2 tens and 2 ones, that is 22 . The same patterns occurs with other triples.

Again we have an example where standard representations are powerful enough to establish a proof.

\subsection{Place Value Chart (Grade 4)}

A good activity for the operative study of the place value chart is provided by the following problem: Which numbers can be represented by 3 (or 2,1 ) counters on a place value chart with four columns?

Children can explore this problem more or less systematically. It is not necessary that all children discover all 20 possible numbers. However, if the children are told that there are in all 20 numbers, there is a good chance that the class as a social body will find them all. It is a nice activity to order them (and to determine the differences of adjacent numbers, particularly if the problems with 2 counters and 1 counter have been solved previously).

In the Mathe 2000 curriculum this combinatorial problem does not come out of the blue but is part of a strand of combinatorics running from grade 1 to 4 . In grade 3 the present problem is prepared by the corresponding problem for the place value chart with three columns.

In grade 1 the children investigate how many different Easter nests can be found with 3 (4) eggs where for the eggs the colors red, blue and yellow are available. These problems are structurally isomorphic to the problems with the place value chart.

In grade 2, 3 and 4 the children determine the number of different shortest ways in a grid from one vertex to another one with a certain distance (measured in the grid metric). 


\section{Conclusion}

The design of a curriculum is only half of the way to reshaping mathematics teaching. In order to get deeper insights into the teaching and learning of mathematics empirical research on a large scale is needed. The research findings will certainly give rise to re-working, modifying and refining the design. In this sense design depends very much on empirical research. But the reverse is equally true. Good design is also a pre-condition for productive empirical research as rich learning environments are much more likely to yield substantial results.

The author is convinced that because of this interdependence of design and empirical research a systematic cooperation between instructional designers and empirical researchers, grounded on a solid theoretical basis, will open a new chapter in the development of mathematics education as a discipline.

Acknowledgements The author is indebted to Adrian J. Pinel, Wilhelm Schipper and Adri Treffers for helpful comments.

\section{References}

Becker, J.P., Selter, Ch.: Elementary school practices. In: Bishop, A.J., Clements, K., Keitel, Ch., Kilpatrick, J., Laborde, C (eds.) International Handbook of Mathematics Education, Part 1. Dordrecht-Boston-London, pp. 511-564 (1996)

Becker, O.: Grundlagen der Mathematik in geschichtlicher Darstellung. Freiburg-München, Karl Alber (1954)

Beth, E.W., Piaget, J.: Épistémologie mathématique et psychologie. Etudes d'épistémologie génétique, vol. XIV (1961)

Bruner, J.S.: The Process of Education. Harvard University Press, Cambridge, Mass (1960)

Cobb, P., Yackel, E., Wood, T.: A constructivist alternative to the representational view of mind in mathematics education. J. Res. Math. Educ. 23, 2-33 (1992)

Comenius, J.A.: Great didactic. Translated into English and edited by M.W. Keatinge. Black, London (1923)

Damerow, P., Lefèvre, W.: Rechenstein, Experiment, Sprache. Historische Fallstudien zur Entstehung der exakten Wissenschaften. Klett Cotta, Stuttgart (1981)

Davis, Ph, Hersh, R.: The mathematical experience. Birkhäuser, Boston (1981)

Dewey, J.: The child and the curriculum. In: Boydston, J.A. (ed.) The Middle Works 1899-1924, vol. 2. SIU Press, Carbondale, Ill, pp. 272-291 (1976)

Dörfler, W.: Wieso kann man mit abstrakten Objekten rechnen? Beiträge zum Mathematikunterricht 1991, pp. 195-198. Franzbecker, Bad Salzdetfurth (1991)

Dress, A.: Ein Brief über Mathematik. In: Otte, M. (ed.) Mathematiker über die Mathematik. Springer, Berlin, Heidelberg, New York (1974)

Flexer, R.J.: The power of five: the step before the power of ten. Arith. Teach. No 2, 5-9 (1986)

Fröbel, F.: Gesammelte pädagogische Werke. Osnabrück: Biblio (Nachdruck)

Gravemeijer, K.: Developing Realistic Mathematics Education. Freudenthal Institute, Utrecht (1994)

Hughes, T.: Winter pollen. Occasional Poems. In: William, S. (ed.) Faber and Faber, London (1994)

Jahnke, H.N.: Abstrakte Anschauung. Geschichte und didaktische Bedeutung. In: Kautschitsch, H., Metzler, W. (eds.) Anschauliches Beweisen, pp. 33-54. Hölder-Pichler-Tempsky, Wien-Stuttgart (1989) 
Kant, I.: Critique of Pure Reason. Translated by J.M.D. Meiklejohn. Willey Book Co, New York

Kaput, J.J.: Representation Systems and Mathematics. In: Janvier, C. (ed.) Problems of representation in the teaching and learning of mathematics, pp. 19-26. Erlbaum, Hillsdale, N. J. (1987)

Krauthausen, G.: Arithmetische Fähigkeiten von Schulanfängern: Eine Computersimulation als Forschungsinstrument und als Baustein eines Softwarekonzeptes für die Grundschule. Reihe "DUV Mathematik". Deutscher Universitätsverlag, Wiesbaden (1994)

Lorenz, J.H.: Anschauung und Veranschaulichungsmittel im Mathematikunterricht. Hogrefe, Göttingen (1992)

Radatz, H.: Anschauung und Sehverstehen, pp. 239-242. Beiträge zum Mathematikunterricht. Bad Salzdetfurth, Franzbecker (1986)

Penrose, R.: Shadows of the mind. OUP, New York, Oxford (1994)

Piaget, J.: Science of Education and the Psychology of the Child. Translated from the French by Derek Coltmann. Orion Press, New York (1970)

Schipper, W.: Stoffauswahl und Stoffanordnung im mathematischen Anfangsunterricht. Journal für Mathematik-Didaktik, H. 2, 91-120 (1982)

Steinbring, H.: The relation between social and conceptual conventions in everyday mathematics teaching. In: Bazzini, L., Steiner, H.-G. (eds.) Proceedings of the Second Italian-German Bilateral Symposium on Didactics of Mathematics, vol. 39, pp. 369-383. Institut für Didaktik der Mathematik. Materialien und Studien Band, Bielefeld (1994)

Tillich, E.: Allgemeines Lehrbuch der Arithmetik oder Anleitung zur Rechenkunst für Jedermann. Heinrich Gräff, Leipzig (1806)

Treffers, A.: Integrated column arithmetic according to progressive schematisation. Educ. Stud. Math. 18, 125-146 (1987)

Treffers, A., de Moor, E.: Proeve van een nationaal programma voor het rekenwiskundeonderwijs op te basisschool. Deel II. Basisvaardigheden en cijferen. Zwijsen, Tilburg (1990)

Voigt, J.: Social functions of routines and consequences for subject matter learning. Int. J. Educ. Res. 13, 647-656 (1989)

Wertsch, J.: Vygotsky and the social function of mind. Harvard University Press, Cambridge, Mass (1985)

Wittmann, ECh.: Teaching units as the integrating core of mathematics education. Educ. Stud. Math. 15, 25-36 (1984)

Wittmann, ECh.: Weniger ist meh: Anschauungsmittel im Mathematikunterricht der Grundschule. Beiträge zum Mathematikunterricht 1993, pp. 394-397. Bad Salzdetfurth, Franzbecker (1993)

Wittmann, E.C.: Mathematics education as a design science. Educ. Stud. Math. 29, 355-374 (1995)

Wittmann, E.Ch.: The pythagorean theorem. In: Cooney, Th.J. et. al. (ed.) Mathematics, Pedagogy and Secondary Teacher Training. Heinemann, Portsmouth, N.H., pp. 97-165

Wittmann, E.Ch., Müller, G.N.: Handbuch produktiver Rechenübungen. Band 1: Vom Einspluseins zum Einmaleins. Klett, Stuttgart (1990)

Wittmann, E.Ch., Müller, G.N.: Handbuch produktiver Rechenübungen. Band 2: Vom halbschriftlichen zum schriftlichen Rechnen. Klett, Stuttgart (1992) 
Open Access This chapter is licensed under the terms of the Creative Commons Attribution 4.0 International License (http://creativecommons.org/licenses/by/4.0/), which permits use, sharing, adaptation, distribution and reproduction in any medium or format, as long as you give appropriate credit to the original author(s) and the source, provide a link to the Creative Commons license and indicate if changes were made.

The images or other third party material in this chapter are included in the chapter's Creative Commons license, unless indicated otherwise in a credit line to the material. If material is not included in the chapter's Creative Commons license and your intended use is not permitted by statutory regulation or exceeds the permitted use, you will need to obtain permission directly from the copyright holder.

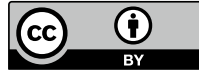

